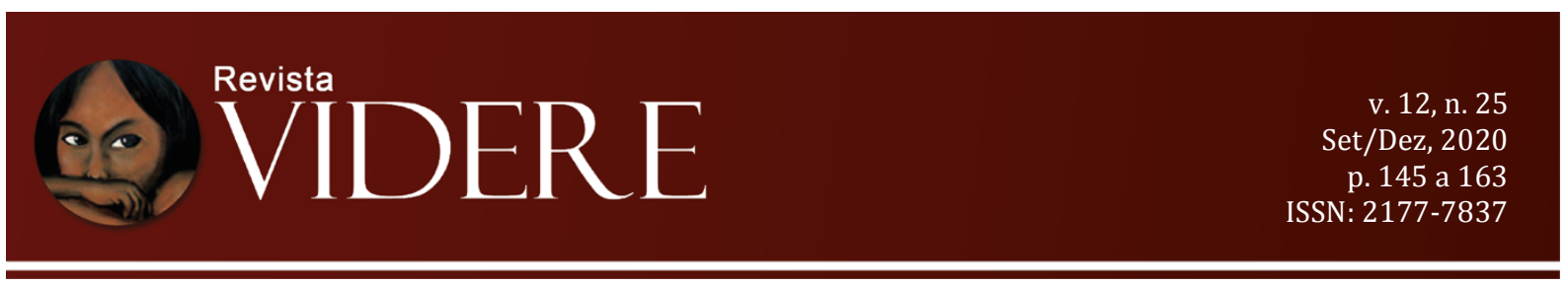

\title{
A DIMENSÃo POLÍTICA DA SEGURANÇA JURÍDICA
}

\author{
THE POLITICAL DIMENSION OF LEGAL CERTAINTY
}

LA DIMENSIÓN POLÍTICA DE LA SEGURIDAD JURÍDICA

\begin{abstract}
Adriana Campos Silva
Doutora em Direito pela Universidade Federal de Minas Gerais.

Mestre em Direito pela UFMG.

Professora da graduação e da pós-graduação stricto sensu em Direito da UFMG.

adrilaw100@gmail.com

OrcidID: https://orcid.org/0000-0002-2871-6778
\end{abstract}

\begin{abstract}
Christiane Costa Assis
Doutoranda em Direito pela Universidade Federal de Minas Gerais. Mestre em Direito pela

Pontifícia Universidade Católica de Minas Gerais.

Professora da graduação em Direito da Universidade do Estado de Minas Gerais. assischris@gmail.com

OrcidID: https://orcid.org/0000-0003-3565-4023
\end{abstract}

\begin{abstract}
Resumo: O presente artigo tem como objetivo analisar a dimensão política da segurança jurídica apresentando construções teóricas sobre o tema e ainda uma abordagem de análise de índices de pesquisa aplicada ao panorama brasileiro. Para tanto, adotou-se o procedimento de pesquisa bibliográfica e o método de abordagem dialético comparativo. Como resultado o artigo apresenta os contornos da segurança jurídica como elemento e garantia da justiça política e sua aplicabilidade no cenário brasileiro. A originalidade do artigo decorre da construção teórica sobre segurança jurídica aplicada aos índices de pesquisa analisados, contribuindo com futuros estudos sobre a democracia no Brasil.
\end{abstract}

Palavras-chave: segurança jurídica. justiça política. confiança. democracia. indicadores.

\begin{abstract}
This article aims to analyze the political dimension of legal certainty by presenting theoretical constructions on the subject and also an approach applied to the Brazilian panorama through research indexes. To this end, the procedure of bibliographic research and the method of comparative dialectic approach were adopted. As a result, the article presents the contours of legal certainty as a requirement and guarantee of political justice and its applicability in the Brazilian scenario. The originality of the article stems from the theoretical construction on legal certainty applied to the research indexes analyzed, contributing to future studies on democracy in Brazil.
\end{abstract}


Keywords: legal certainty. political justice. trust. democracy. indicators.

Resumen: Este artículo tiene como objetivo analizar la dimensión política de la seguridad jurídica mediante la presentación de construcciones teóricas sobre el tema y también un enfoque de análisis de índices de investigación aplicados al panorama brasileño. Para eso se adoptó el procedimiento de investigación bibliográfica y el método de enfoque dialéctico comparado. En consecuencia, el artículo presenta los contornos de la seguridad jurídica como elemento y garantía de la justicia política y su aplicabilidad en el escenario brasileño. La originalidad del artículo surge de la construcción teórica sobre la seguridad jurídica aplicada a los índices de investigación analizados, contribuyendo a futuros estudios sobre la democracia en Brasil.

Palabras clave: seguridad jurídica. justicia política. confianza. democracia. indicadores.

\section{Introdução}

A segurança jurídica é frequentemente associada às ideias de certeza, previsibilidade, estabilidade, confiança e expectativa. Tais ideias são atributos da segurança jurídica, sendo impossível defini-la taxativamente de forma conceitual em função suas diferentes dimensões na esfera jurídica. Dentro dessa temática fala-se ainda nos institutos do direito adquirido, ato jurídico perfeito e coisa julgada, todos marcados pelas ideias já mencionadas. Entre as dimensões da segurança jurídica encontra-se a dimensão política, que se refere não apenas aos direitos políticos, mas à justiça política.

O presente artigo pretende analisar os contornos da segurança jurídica vinculada à ideia de justiça política, apontando os desafios para a sociedade contemporânea marcada pelo cenário de desconfiança nas instituições. Para tanto, o artigo apresentará inicialmente uma construção teórica sobre a segurança jurídica, destacando o diálogo entre autores que tratam sobre o tema. Em seguida, será apresentado o panorama atual da confiança no Brasil com base no Índice de Confiança Social (ICS) elaborado pelo Instituto Brasileiro de Opinião Pública e Estatística - IBOPE e no Latinobarômetro elaborado pela Organização Não Governamental Corporación Latinobarómetro.

No aspecto metodológico adotou-se o procedimento de pesquisa bibliográfica e análise de dados secundários, utilizando-se o método de abordagem dialético comparativo. Como resultado, espera-se apresentar os contornos da segurança jurídica no contexto da justiça política e aplicar tal construção teórica ao cenário brasileiro conforme os dados levantados pelo IBOPE e pelo Latinobarômetro. 


\section{Segurança jurídica e justiça política}

Por um longo tempo os poderes públicos confiaram aos órgãos judiciais a segurança formal dos atos privados, o que foi potencializado pela revolução burguesa que buscou tais órgãos para garantia do direito subjetivo de propriedade considerado o principal direito no ordenamento jurídico liberal individualista (PÉREZ LUÑO, 1990, p. 330). Entretanto os desacordos entre particulares e Estado sobre o conteúdo da segurança mantiveram vivas as discussões sobre seu conteúdo. O esboço conceitual teve início com o constitucionalismo democrático que situou a garantia dos direitos e liberdades no vértice das funções estatais (PÉREZ LUÑO, 1990, p. 331). Os ataques mais implacáveis contra a segurança jurídica ocorreram em períodos totalitários, por meio de impugnações de sua significação que seria conformista e antiteórica ou ainda a reputando como produto da ideologia burguesa e antiigualitária (PÉREZ LUÑO, 1990, p. 331). Entretanto, com o constitucionalismo democrático a segurança jurídica restou protegida de manipulações e se tornou essencial para os valores da justiça e da paz social (PÉREZ LUÑO, 1990, p. 331). Dessa forma, a segurança jurídica perdeu seu aspecto antitético da justiça e se converteu em componente e também em promotora desta, assumindo um papel de valor e princípio de tripla proteção (PÉREZ LUÑO, 1990, p. 331): inspira as relações entre Estado e cidadãos na esfera pública, garante a autonomia da vontade nas relações jurídico-privadas e impulsiona a liberdade civil no limite entre público/privado por remover os obstáculos que desvirtuam a liberdade entre os desiguais (PÉREZ LUÑO, 1990, p. 332).

A superação da tensão entre segurança jurídica e justiça adveio a partir da concretização de ambos os valores. A segurança jurídica afastou-se da simples identificação como de legalidade e positividade do Direito para se aproximar com os bens jurídicos básicos que necessariamente devem ser assegurados (PÉREZ LUÑO, 1990, p. 335). Por sua vez, a justiça se afastou de um conceito ideal e abstrato para incorporar as exigências democráticas e igualitárias que compõem o Estado Democrático de Direito (PÉREZ LUÑO, 1990, p. 335).

A releitura da segurança jurídica a partir de bens jurídicos básicos não escapa de críticas. O caráter impreciso e equívoco da noção de bens jurídicos abre espaço para tautologias ao se adotar definições como "bens que incumbem a todos", "bens que o Direito deve proteger", entre outros (PÉREZ LUÑO, 1990, p. 336). Além disso, a amplitude e a natureza difusa desses bens que devem ser juridicamente tutelados transporta um elemento de insegurança para a segurança jurídica (PÉREZ LUÑO, 1990, p. 336). Tal indefinição abre espaço para a identificação desses bens com interesses puramente individuais ou ainda com 
interesses dos detentores do poder político - ambos os casos não são admissíveis em um Estado Democrático de Direito (PÉREZ LUÑO, 1990, p. 337). Há ainda o risco de o Estado utilizar a segurança jurídica pelo Estado como argumento para obter adesão incondicionada de suas medidas de controle social restritivas de liberdade (PÉREZ LUÑO, 1990, p. 337).

No intuito de evitar os problemas advindos da indefinição conceitual os bens jurídicos devem buscar uma identificação com os valores constitucionalmente proclamados pelos Estados de Direito que são mais precisos, o que permite uma concreção definitiva dos bens jurídicos no próprio sistema dos direitos fundamentais (PÉREZ LUÑO, 1990, p. 337). O problema da identificação dos bens jurídicos com interesses individuais ou interesses dos detentores do poder encontra solução no Estado Democrático de Direito que concebe os direitos fundamentais como forma de integração plena e simultânea das exigências pessoais e sociais (PÉREZ LUÑO, 1990, p. 337/338). Assim sendo, os direitos e liberdades não são garantias negativas - de não interferência do Estado na esfera privada - por demandarem a remoção de obstáculos de ordem econômica, social e cultural que impedem a plena realização da liberdade e da igualdade humana (PÉREZ LUÑO, 1990, p. 338). Quanto ao risco de utilização pelo Estado da segurança jurídica como argumento de adesão incondicionada, o Estado Democrático de Direito consegue impedir a evolução autoritária estatal com uma estrutura responsiva aos princípios do pluralismo e da participação democrática (PÉREZ LUÑO, 1990, p. 338). Nessa estrutura, as decisões partem de um consenso intersubjetivo resultante de procedimentos imparciais a partir das necessidades humanas, não podendo ser uma imposição arbitrária de um grupo ideológico (PÉREZ LUÑO, 1990, p. 338).

A crescente judicialização da política fez com que o Estado de Direito privilegiasse o Direito Político, se convertendo em Estado de Direito Político (MARTINEZ, 2005, p. 08). Entretanto, "essa atividade migratória da política levou o Direito a relacionar sentidos controversos, como: indefinição, incerteza, idiossincrasias" (MARTINEZ, 2005, p. 08), dentre outros adjetivos causadores de insegurança jurídica. Lado outro, a carência de legitimidade das decisões na esfera pública fez a justiça se aproximar dos direitos políticos, falando-se em justiça política. A segurança jurídica como pressuposto da justiça política é um princípio irrenunciável de legitimação, devendo revelar uma regulação social e sua forma jurídica legítima (HÖFFE, 2006, p. 56). As ideias comumente atreladas à segurança jurídica possuem contornos jurídicos próprios dentro da justiça política.

Sob a égide da justiça política a segurança jurídica se relaciona à previsibilidade não dos resultados eleitorais, mas dos procedimentos e da periodicidade dos pleitos eleitorais. As regras eleitorais precisam ser conhecidas previamente evitando-se surpresas e, nesse sentido, 
fala-se em anterioridade (ou anualidade) das leis eleitorais ${ }^{1}$. A intenção é evitar mudanças súbitas que possam interferir nos resultados eleitorais. Isso não implica uma imutabilidade das regras eleitorais, mas garante aos atores do pleito eleitoral um período de adaptação. Lado outro, "[...] espera-se que as instâncias do poder encarregadas de garantir o Direito promovam as atualizações necessárias, renovando-o e adaptando-o às situações que surgem a cada dia" (CAMARGO, 2012, p. 03), mas espera-se que as mudanças não ensejem rupturas bruscas no processo eleitoral, devendo haver observância do devido processo legislativo para as leis e de parâmetros para a jurisprudência (CAMARGO, 2012, p. 13 e ss.).

A segurança jurídica também se relaciona com a confiança nos procedimentos eleitorais, no sentido de que as regras serão efetivamente observadas por todos. Além disso, é preciso haver confiança na igualdade, ou seja, confiança na ausência de distinções de qualquer natureza, exceto aquelas legalmente previstas e devidamente embasadas na isonomia - é o caso, por exemplo, das cotas para candidaturas de mulheres.

Para alguns a democracia nasceu da desconfiança em relação aos detentores do poder e aos procedimentos habituais de manutenção desse poder (MOISÉS, 2005, p. 85). Nesse contexto, a adoção de regras e instituições democráticas permite o controle, a limitação e a distribuição do poder (MOISÉS, 2005, p. 85). A democracia cria normas de procedimentos para escrutinizar os poderes discricionários implícitos nas relações de poder, resultando em uma supervisão e monitoramento do exercício do poder pelos cidadãos (MOISÉS, 2005, p. 85). Isso significa que a democracia necessariamente trabalha com a desconfiança e opera com normas e instituições criadas para o controle dos riscos de origem, o que dificulta a confiança política (MOISÉS, 2005, p. 85). A solução perpassa pela institucionalização de regras e normas que asseguram um padrão civilizado de competição política apesar da impossibilidade de garantia absoluta de que os conflitos de interesses divergentes possam ser resolvidos pacificamente (MOISÉS, 2005, p. 85).

Mecanismos como eleições, representação, liberdade de expressão e de associação, direito de julgamento justo e imparcial, separação de poderes e a obrigação de prestação de contas por governos capacitam os cidadãos para desafiar as relações de que desconfiam, mas para fazer isso, a sua desconfiança precisa ser "institucionalizada", ou seja, tornada permanente através de regras que, uma vez mobilizadas, asseguram que eles podem competir por seus interesses sem riscos para sua liberdade e para seus direitos (MOISÉS, 2005, p. 85/86).

\footnotetext{
${ }^{1}$ Nos termos do art. 16 da Constituição de 1988, “a lei que alterar o processo eleitoral entrará em vigor na data de sua publicação, não se aplicando à eleição que ocorra até um ano da data de sua vigência" (BRASIL, 1988). 
A institucionalização da desconfiança exige a aceitação pelos cidadãos das regras que garantem o direito de controle das circunstâncias que geram a desconfiança, o que é possível por meio das instituições democráticas (MOISÉS, 2005, p. 86). Uma vez que as instituições se mostrem sensíveis aos interesses dos cidadãos e demonstrem pautar seus procedimentos no universalismo, imparcialidade, justeza e probidade, elas conquistarão a confiança dos cidadãos (MOISÉS, 2005, p. 91). Lado outro, a indiferença institucional em face das demandas populares, práticas de corrupção e de fraude e desrespeito ao interesse público causam descrédito e desesperança, comprometendo a aceitação das leis e estruturas que regulam a vida social (MOISÉS, 2005, p. 91/92). Estabelecer regras e procedimentos que gerem confiança para serem aceitos pelos cidadãos, entretanto, consiste em tarefa árdua.

Niklas Luhmann considera que o procedimento eleitoral é marcado por determinadas características que o diferenciam do processo judicial, tais como: existência de papeis especiais (eleitores, candidatos, presidente eleitoral, mesários, etc.), incerteza do resultado, transmissão da competência do cargo a ser preenchido independentemente de uma margem maior ou menor de votos do vencedor, impossibilidade de o eleitor reforçar a eficácia de seu voto, dentre outras (LUHMANN, 1980, p. 131 e ss.). No processo eleitoral três princípios garantem a distribuição de papéis e a diferenciação: universalidade (ainda que com exigências legalmente estabelecidas) do acesso ao papel de leitor, igualdade de peso dos votos e segredo da votação (LUHMANN, 1980, p. 134).

Para Luhmann processo eleitoral legalmente institucionalizado consegue reproduzir oposições e solucionar conflitos. Cada vitória eleitoral possui importância provisória, pois nas eleições seguintes os derrotados poderão renovar suas esperanças (LUHMANN, 1980, p. 135). A eleição periódica permite que o sistema político se oriente pela sua própria história (LUHMANN, 1980, p. 140), convertendo-se em um "[...] mecanismo por meio do qual o sistema político se auto sanciona e a decisão político-administrativa do passado confirma ou rejeita" (LUHMANN, 1980, p. 141). Nesse contexto, a legitimidade consiste em uma reestruturação de expectativas, pois a eleição política é uma oportunidade de expressar insatisfação (LUHMANN, 1980, p. 141). Entre os eleitores há uma confiança negativa por meio da percepção de que todos estão em situação semelhante e de que nenhum deles será favorecido (LUHMANN, 1980, p. 142). Luhmann acredita que essa confiança negativa empurra as desigualdades para o segundo plano e, assim sendo, embora o mecanismo eleitoral não permita uma democracia com participação igualitária de todos no poder, há o assentamento do princípio da igualdade na base do processo de alistamento político (LUHMANN, 1980, p. 142). Conclui o autor que a eleição proporciona ao sistema político 
uma complexidade elevada e uma indeterminação estrutural, além de certa impossibilidade de cálculo do resultado que serve de estímulo para a construção interna do sistema e eliminação de alternativas (LUHMANN, 1980, p. 142).

Höffe critica a proposta de Luhmann por ser uma "legitimação exclusivamente através do procedimento" (HÖFFE, 2006, p. 147), na qual as decisões recebem uma autorização puramente formal e não material (HÖFFE, 2006, p. 150). Para Höffe é necessário considerar a legitimidade pelo viés da justiça política.

A justiça política está no âmbito da justiça institucional, ou seja, é justiça de uma entidade de direito e de Estado se diferenciando da justiça pessoal (HÖFFE, 2006, p. 42). A justiça política submete as leis e as instituições políticas a uma crítica ética, assumindo a ideia ética de direito e de Estado - trata-se do filtro para a distinção entre forma legítimas e nãolegítimas de direito e de Estado (HÖFFE, 2006, p. 01). As estratégias de justiça política são os procedimentos para comprometer o máximo possível os poderes públicos com a justiça e subdividem em estratégias de positivação (o reconhecimento histórico e concreto dos princípios da justiça) e as estratégias de julgamento (nova determinação das formas jurídicas que devem ser reconhecidas) (HÖFFE, 2006, p. 412). Essas estratégias são necessárias porque os detentores do poder podem "esquecer" suas atribuições, atendendo suas paixões em detrimento da justiça e buscando o poder por ele mesmo (HÖFFE, 2006, p. 411).

A democracia se relaciona com o significado de justiça, uma vez que os direitos democráticos de coparticipação integram os Direitos Humanos que são princípios médios de justiça (HÖFFE, 2006, p. 413). Na democracia esses princípios possuem a função de proteção de minorias, além de garantir direitos iguais aos que não compartilham com a maioria as mesmas convicções econômicas, sociais, políticas, religiosas ou linguístico-culturais sendo, portanto, "[...] um corretivo crítico contra os excessos da soberania, mesmo de um soberano democrático" (HÖFFE, 2006, p. 416). Para garantir tais princípios médios de justiça não apenas momentos políticos favoráveis é necessário institucionalizá-los, pois por meio dessa positivação tais direitos deixam de ser simples ideias, esperanças, postulados ou declarações solenes de intenção e para se tornarem parte obrigatória da ordem do Direito e do Estado: "[...] eles perderam o caráter de simples princípios de legitimidade e se tornaram princípios de legalidade" (HÖFFE, 2006, p. 416). A positivação não tem o condão de salvaguardar tais direitos de questionamentos e problemas da efetividade, mas ao menos reforça sua exigibilidade. 
Para Höffe (HÖFFE, 2006, p. 417) aos Direitos Humanos faltam a força jurídica positiva dos direitos fundamentais, pois apesar de possuírem o mesmo conteúdo o modo de existência desses direitos é diferente:

Os Direitos humanos são padrões morais, aos quais uma ordem jurídica se deveria submeter. Os direitos fundamentais ao contrário são os direitos humanos, na medida em que efetivamente são reconhecidos por uma ordem jurídica dada. Lá se trata de postulados ético-políticos, os quais, do ponto de vista do tempo e do espaço, são universais. Aqui se trata de normas jurídicas que, limitadas à respectiva coletividade, têm vigência positiva (HÖFFE, 2006, p. 417).

Höffe entende que a positivação dos Direitos Humanos do ponto de vista da teoria da legitimação somente ocorre no Estado democrático constitucional (HÖFFE, 2006, p. 416) e o reconhecimento como princípios positivos realizou-se nas revoluções americanas e francesa para então serem assumidos em outros Estados (HÖFFE, 2006, p. 419). Há um duplo significado no reconhecimento jurídico positivo dos Direito Humanos: primeiramente, são pretensões de seres humanos em face dos outros; secundariamente, são pretensões contra a instância que deve proteger as pretensões do Estado (HÖFFE, 2006, p. 419). São, portanto, "pretensões ameaçadas pelo próprio 'poder de proteção"' (HÖFFE, 2006, p. 419) - daí a importância de positivação, formando o núcleo fundamental das Constituições dos Estados.

A segurança jurídica integra os direitos fundamentais das Constituições e, portanto, também é princípio médio da justiça política. Sem segurança jurídica não há plenitude de justiça, mas ela própria demanda a realização de todo o núcleo fundamental sob pena de insegurança. Nesse sentido, a segurança jurídica é, concomitantemente, requisito e garantia da justiça política.

\section{Um panorama brasileiro sobre a (des)confiança}

O Índice de Confiança Social (ICS) ${ }^{2}$ elaborado pelo Instituto Brasileiro de Opinião Pública e Estatística - IBOPE aponta que as instituições brasileiras gradativamente perderam a confiança da população nos últimos 9 anos, mas em 2019 a confiança aumentou (IBOPE,

2 Sobre o índice: "Realizado desde 2009, sempre no mês de julho, o Índice de Confiança Social (ICS) é medido em uma escala que vai de 0 a 100, sendo 100 o índice máximo de confiança. A pesquisa foi realizada entre os dias 11 e 15 de julho, com 2.002 pessoas a partir de 16 anos, em 144 municípios do país. A margem de erro é de dois pontos percentuais para mais ou para menos sobre os resultados encontrados no total da amostra" (IBOPE. 2019a). 
2019b). O índice considera a confiança da população em instituições ${ }^{3}$ (ICS Instituições) e nas pessoas e grupos sociais (ICS Pessoas e Grupos Sociais) ${ }^{4}$ e é construído da seguinte forma: os entrevistados avaliam com códigos de resposta cada instituição ou grupo social. Os códigos de resposta variam em uma escada de 0 a 100: muita confiança (100), alguma confiança (66), quase nenhuma confiança (33), nenhuma confiança (0). Faz-se uma média simples para cada instituição ou grupo social (IBOPE, 2019b).

O Latinobarômetro é o índice produzido pela Organização Não Governamental Corporación Latinobarómetro, sediada em Santiago do Chile (LATINOBARÓMETRO, 2019, p. 03). As pesquisas se iniciaram no ano de 1995 e cada elemento analisado adota metodologia própria. Para análise das instituições, os entrevistados responderam à seguinte pergunta: "Por favor, observe esse cartão e me diga para cada um(a) dos grupos/instituições ou pessoas mencionadas na lista: quanta confiança você tem nelas: muita, alguma, pouca ou nenhuma confiança em....?" Os dados da confiança nas instituições apresentados neste artigo apontam o somatório das respostas "muita" e "algo" (LATINOBARÓMETRO, 2018, p. 51).

Embora todos os elementos pesquisados nos índices se relacionem em alguma medida com os Direitos Humanos, a análise no presente artigo focará nas instituições-chave para a justiça política: Ministério Público, Poder Judiciário e Justiça, Governo da Cidade Onde Mora, Eleições e Sistema Eleitoral, Governo Federal, Congresso Nacional, Partidos Políticos e Presidente da República. A abordagem dos dados será no sentido de comparar os números de 2009 (ano de início do ICS) com os números de 2018 e ainda comparar os números de 2018 com os números de 2019. A intenção é demonstrar que de 2009 a 2018 a confiança estava em declínio generalizado no Brasil, mas em 2019 todos os índices apresentaram aumento. Além disso, comparar-se-á o índice brasileiro de 2018 com o índice geral da América Latina no intuito de se verificar a sincronia ou não do Brasil com a tendência dos países vizinhos. Entretanto, como existem diferenças nos itens pesquisados pelo Índice de Confiança Social e pelo Latinobarômetro, para alguns deles a comparação não será possível.

O Ministério Público somente passou a integrar a pesquisa do Índice de Confiança Social a partir de 2016 e, portanto, não possui índices anteriores ao referido ano. Em 2016 o ICS do Ministério Pública era de 54, se manteve igual no ao de 2017, em 2018 caiu para 49 e

\footnotetext{
${ }^{3}$ Instituições que integram a pesquisa: Corpo de Bombeiros; Igrejas; Polícia Federal; Forças Armadas; Escolas Públicas; Polícia; Meios de Comunicação; Empresas; Bancos; Organizações da Sociedade Civil; Ministério Público; Poder Judiciário e Justiça; Sistema Público de Saúde; Sindicatos; Governo da cidade onde mora; Eleições e Sistema Eleitoral; Governo Federal; Congresso Nacional; Partidos Políticos; Presidente da República (IBOPE, 2019b).

${ }^{4}$ Integram a pesquisa sobre pessoas e grupos sociais: pessoas da sua família; seus amigos; seus vizinhos; brasileiros de modo geral. (IBOPE, 2019b).
} 
em 2019 subiu para 59 atingindo seu maior índice. O acréscimo de 10 pontos de 2018 para 2019 significou um aumento de aproximadamente $20 \%$ na confiança.

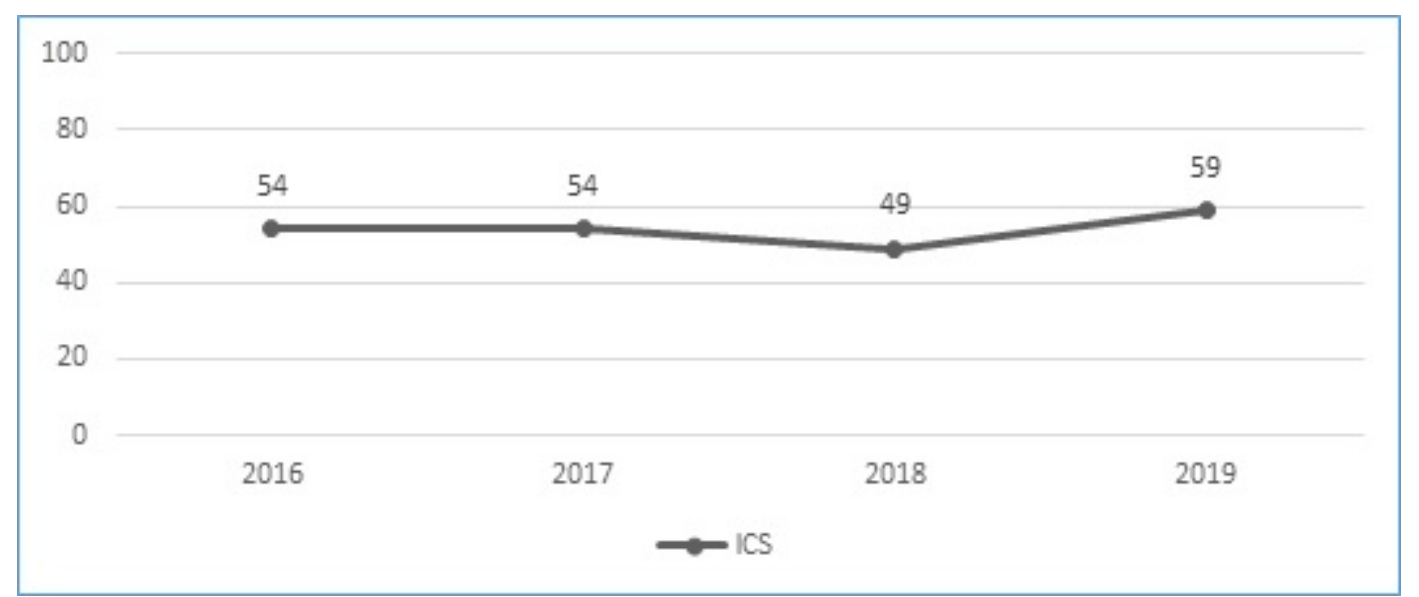

Gráfico 1 - Índice de Confiança Social no Ministério Público. Fonte: IBOPE, 2019b

O ICS do Poder Judiciário e Justiça apresenta oscilações desde 2009, mas atingiu seu pior índice em 2018: 43, sendo que em 2017 era 48. Comparando-se o resultado de 2009 com o de 2018 houve uma queda de 9 pontos, significando um aumento de aproximadamente 17\% na desconfiança. Entretanto, no ano de 2019 o índice atingiu sua maior pontuação: 55, representando um aumento de aproximadamente $28 \%$ na confiança em relação ao ano de 2018.

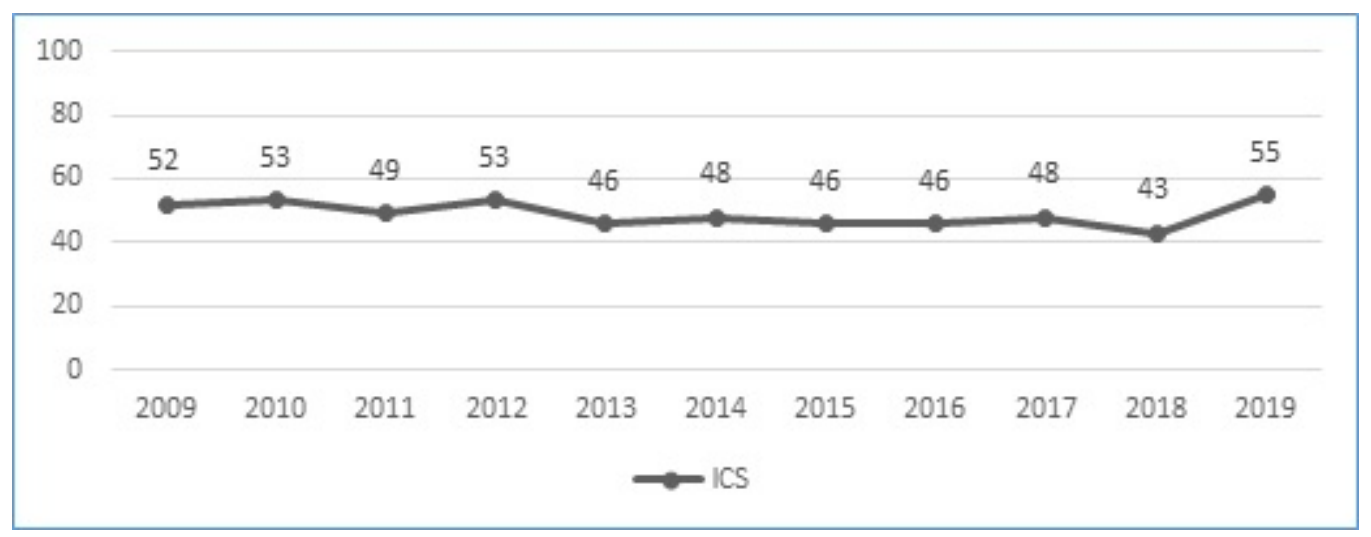

Gráfico 2 - Índice de Confiança Social no Poder Judiciário e Justiça. Fonte: IBOPE, 2019b

O Latinobarômetro possui índice de confiança no Poder Judiciário: no ano de 2018 o Brasil registrou 33\% de confiança, ficando acima da média da América Latina que é de 24\% (LATINOBARÓMETRO, 2018, p. 51). 
O ICS do item Eleições e Sistema Eleitoral apresenta oscilações e, apesar da elevação para 35 pontos em 2017 (em 2016 estava em 37 pontos), atingiu novamente seu pior índice em 2018 repetindo os 33 pontos de 2015. Comparando-se os anos de 2009 e 2018 houve queda de 16 pontos, significando um aumento de aproximadamente 33\% na desconfiança. Em 2019 o índice subiu em 15 pontos, representando um aumento de aproximadamente 45\% na confiança em relação a 2018.

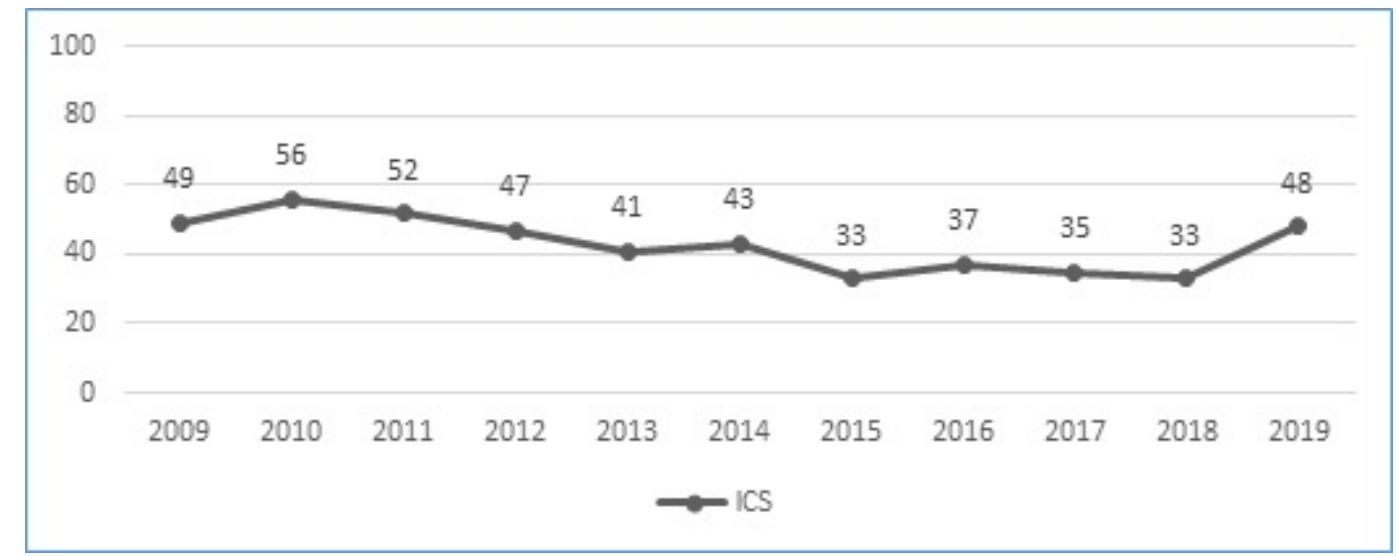

Gráfico 3 - Índice de Confiança Social nas Eleições e Sistema Eleitoral. Fonte: IBOPE, 2019b

O Latinobarômetro possui índice de confiança na Instituição Eleitoral: no ano de 2018 o Brasil registrou 26\% de confiança, ficando abaixo da média da América Latina que é de 28\% (LATINOBARÓMETRO, 2018, p. 54). Especificamente sobre a Justiça Eleitoral, Cunha e Oliveira (CUNHA, 2014, p. 205; 208) afirmam que a desconfiança é fruto da incerteza sobre sua independência, uma vez que em pesquisa realizada pelas autoras $50 \%$ do entrevistados afirmaram que a Justiça Eleitoral atua de forma pouco ou nada independente.

O ICS dos Partidos Políticos apresenta oscilações desde 2009, mas atingiu seu pior índice em 2018: 16, sendo que em 2017 era de 17. Comparando-se os anos de 2009 e 2018, houve queda de 15 pontos, significando um aumento de aproximadamente $48 \%$ na desconfiança. Em 2019 houve aumento de 11 pontos, significando um aumento de aproximadamente 69\% na confiança em relação a 2018. 


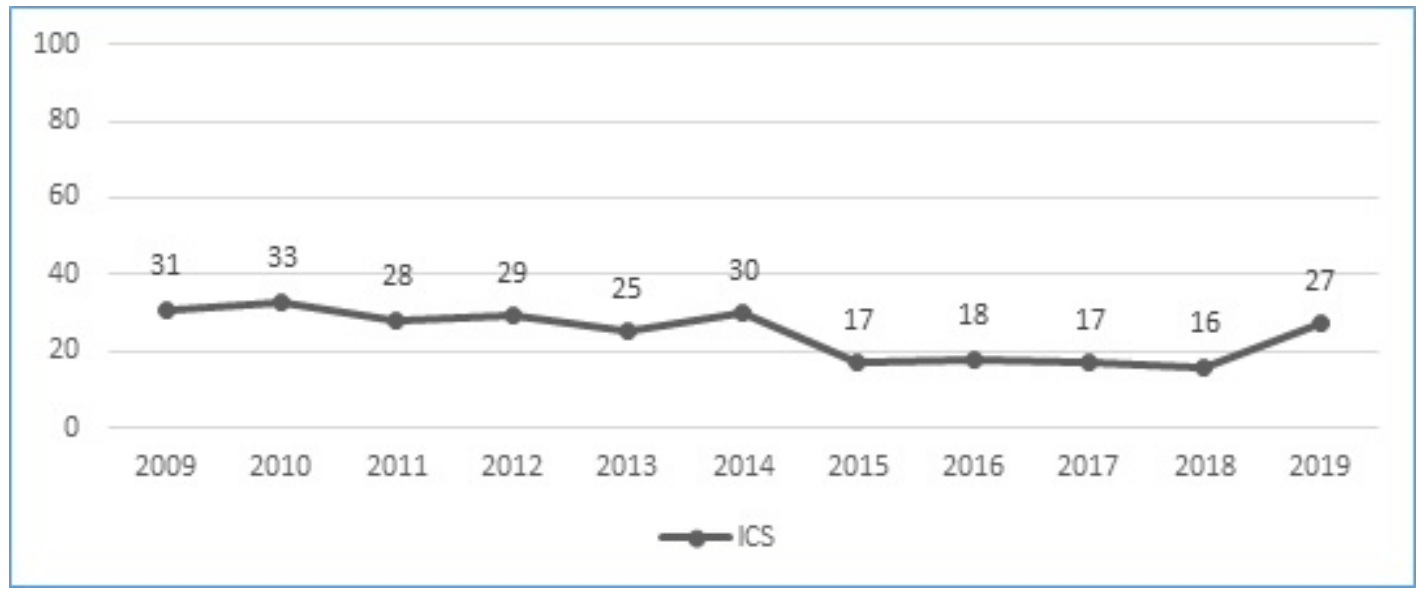

Gráfico 4 - Índice de Confiança Social no Partidos Políticos. Fonte: IBOPE, 2019b

O Latinobarômetro possui índice de confiança nos Partidos Políticos: no ano de 2018 o Brasil registrou 6\% de confiança, ficando abaixo da média da América Latina que é de 13\% (LATINOBARÓMETRO, 2018, p. 53).

O ICS do Governo da Cidade Onde Mora estava em declínio desde o ano de 2009 (exceto no ano de 2014 no qual houve elevação de 1 ponto) e atingiu seu pior índice em 2016: 32, sendo que em 2017 era 38. Comparado ao ano de 2009, o ano de 2018 apresentou queda de 09 pontos, significando um aumento de aproximadamente $17 \%$ na desconfiança. Em 2019 o índice subiu 10 pontos em relação à 2018, significando um aumento de aproximadamente $29 \%$ na confiança.

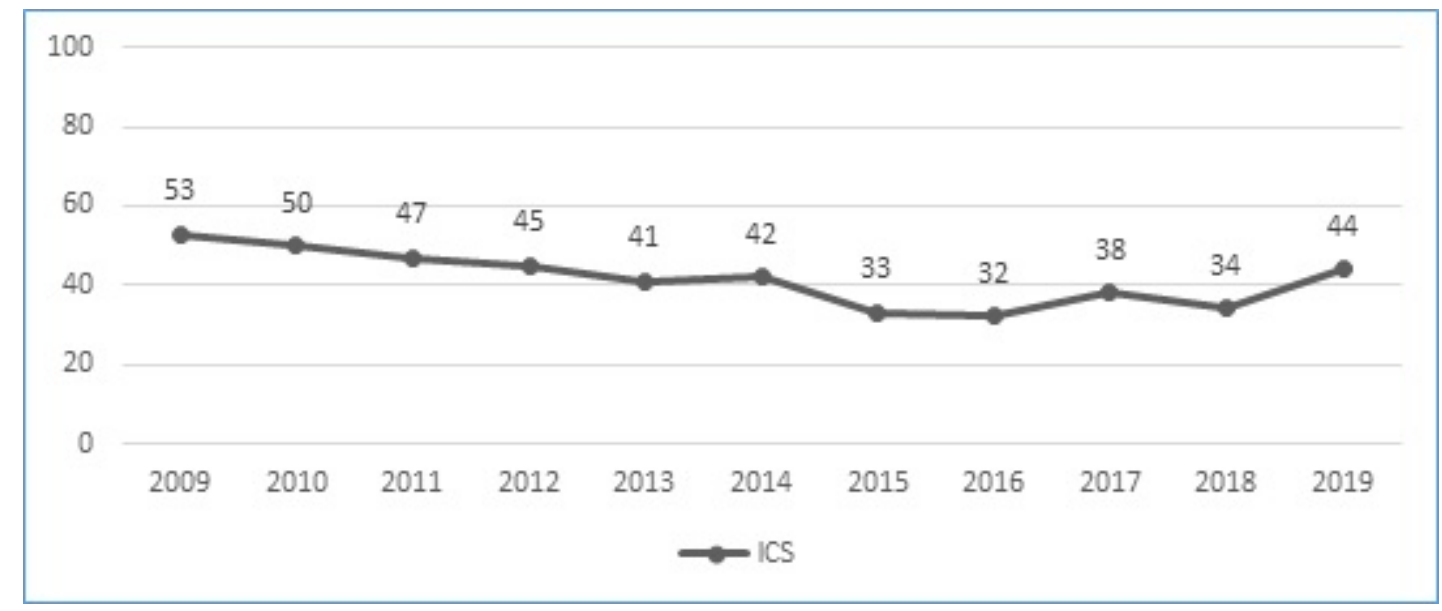

Gráfico 5 - Índice de Confiança Social no Governo da Cidade Onde Mora. Fonte: IBOPE, 2019 b.

O ICS do Governo Federal apresenta oscilações e também períodos de manutenção, mas atingiu seu pior índice em 2018: 25. Comparando-se os anos de 2009 e 2018 houve 
queda de 28 pontos, significando um aumento de aproximadamente 53\% na desconfiança. Em 2019 houve aumento de 25 pontos, o que representa o dobro da confiança no ano de 2018.

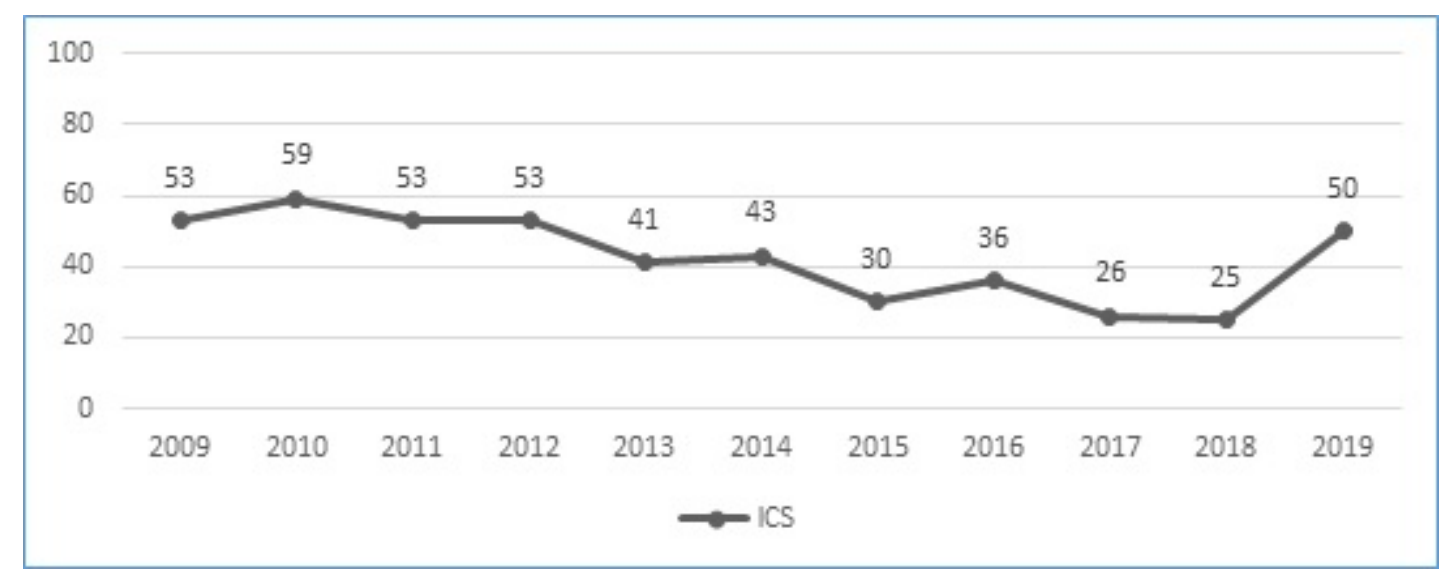

Gráfico 6 - Índice de Confiança Social no Governo Federal. Fonte: IBOPE, 2019b.

O Latinobarômetro possui índice de confiança no Governo: no ano de 2018 o Brasil registrou $7 \%$ de confiança, ficando abaixo da média da América Latina que é de 22\% (LATINOBARÓMETRO, 2018, p. 53).

O ICS do Congresso Nacional apresenta oscilações e períodos de manutenção, mas atingiu seu pior índice em 2017 qual seja, 18, e se manteve assim em 2018. Comparando-se o ano de 2018 com 2009 houve queda de 17 pontos, significando um aumento de aproximadamente 49\% na desconfiança. Em 2019 houve aumento de 16 pontos, significando um aumento de aproximadamente 89\% na confiança em relação a 2018.

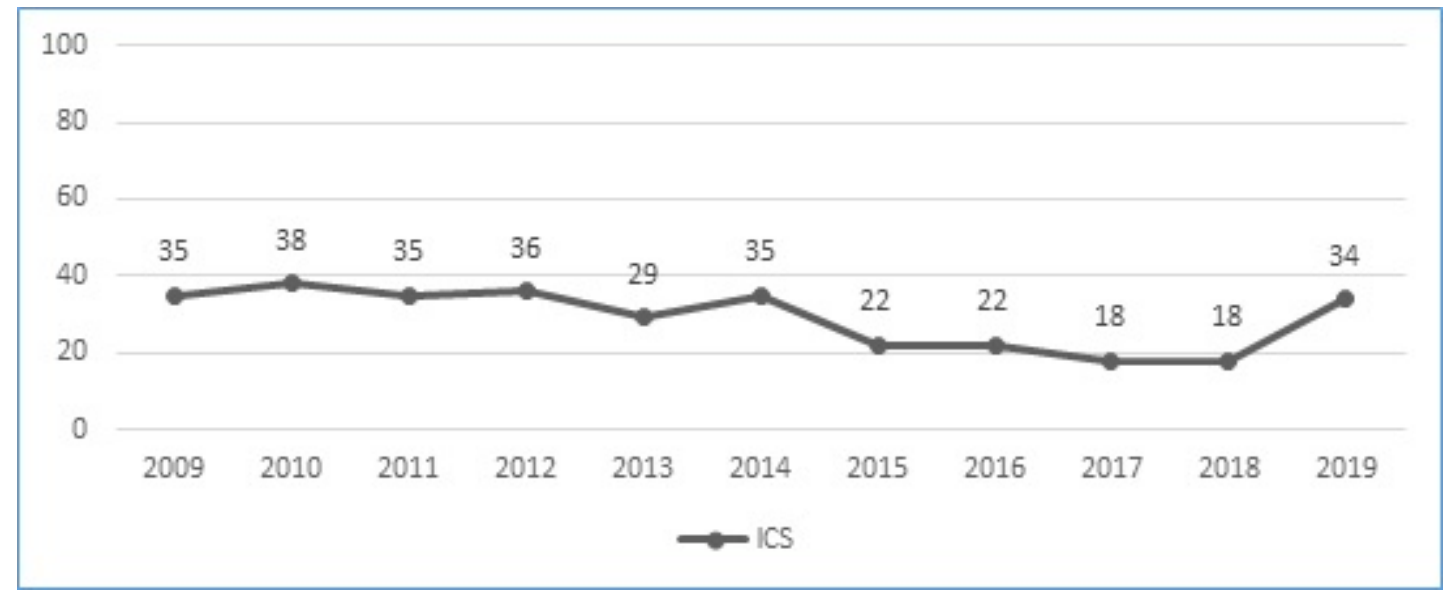

Gráfico 7 - Índice de Confiança Social no Congresso Nacional. Fonte: IBOPE, 2019b. 
O Latinobarômetro possui índice de confiança no Congresso Nacional: no ano de 2018 o Brasil registrou 12\% de confiança, ficando abaixo da média da América Latina que é de 21\% (LATINOBARÓMETRO, 2018, p. 52).

O ICS do Presidente da República apresenta oscilações desde 2009, mas atingiu seu pior índice em 2018: 13, sendo que em 2017 era de 14. Comparando-se os anos de 2009 e 2018 houve queda de 53 pontos, significando um aumento de aproximadamente $80 \%$ na desconfiança. Em 2019 não houve divulgação desse índice.

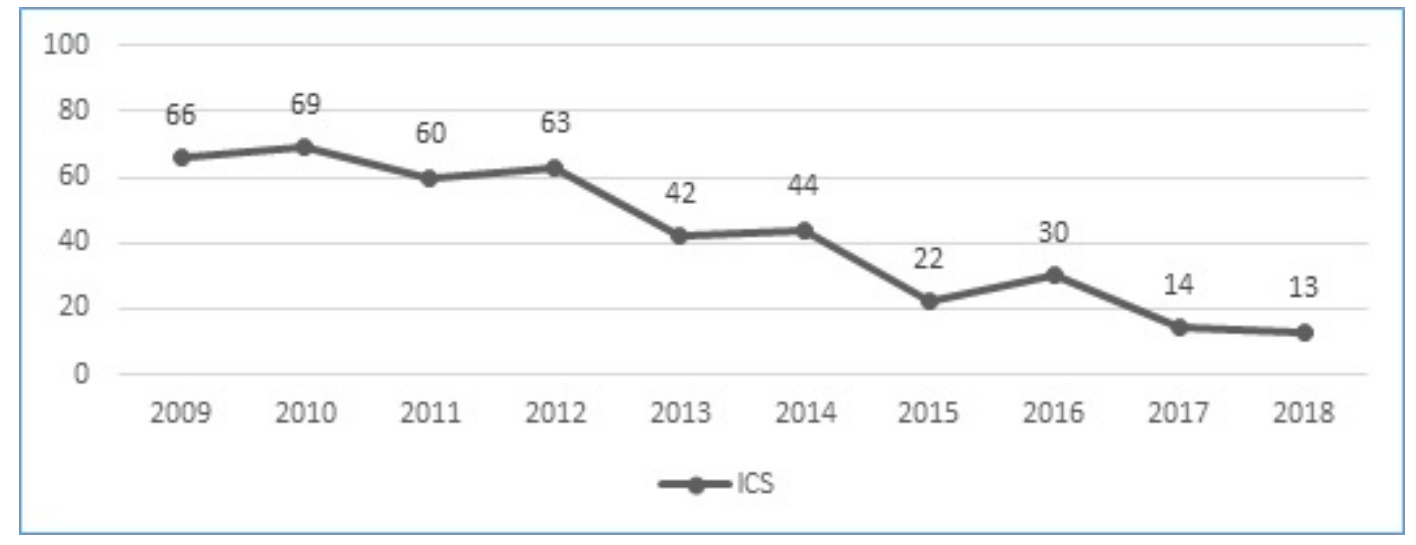

Gráfico 8 - Índice de Confiança Social no Presidente da República. Fonte: IBOPE, 2019b

Quase todas as instituições analisadas no Índice de Confiança Social apresentaram piora em 2018 relação ao índice de $2009^{5}$, evidenciando um declínio generalizado da confiança. Entretanto, no ano de 2019 a confiança em todas as instituições aumentou, subindo o ICS Instituições em 12 pontos, o que significou um aumento de aproximadamente $27 \%$ na confiança em relação a 2018.

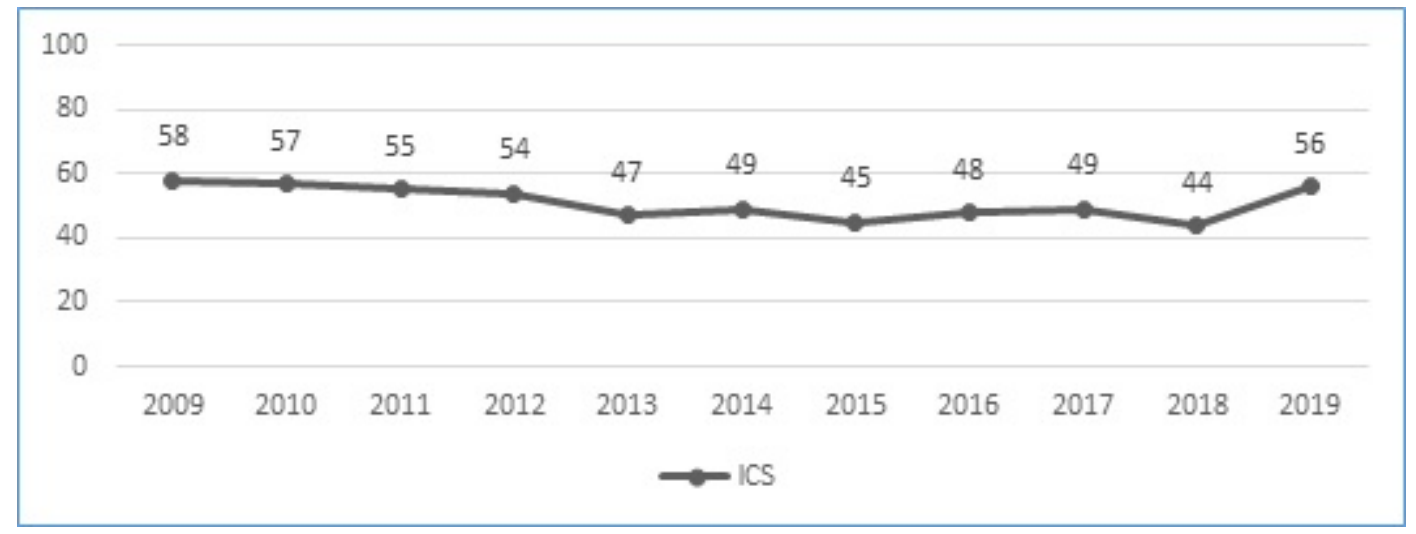

Gráfico 9 - ICS Instituições. Fonte: IBOPE, 2019b

${ }^{5}$ O único índice de 2018 melhor do que o índice de 2009 é o da Polícia (52 em 2009 e 53 em 2018), mas o ano de maior confiança nessa instituição é o de 2019 (63 pontos) (IBOPE, 2019b). 
A elevação do ICS Instituições em 2019 foi a principal responsável pela elevação do Índice de Confiança Social em 20196\% o acréscimo de 10 pontos significou um aumento da confiança de aproximadamente $21 \%$ em relação ao ano de 2018.

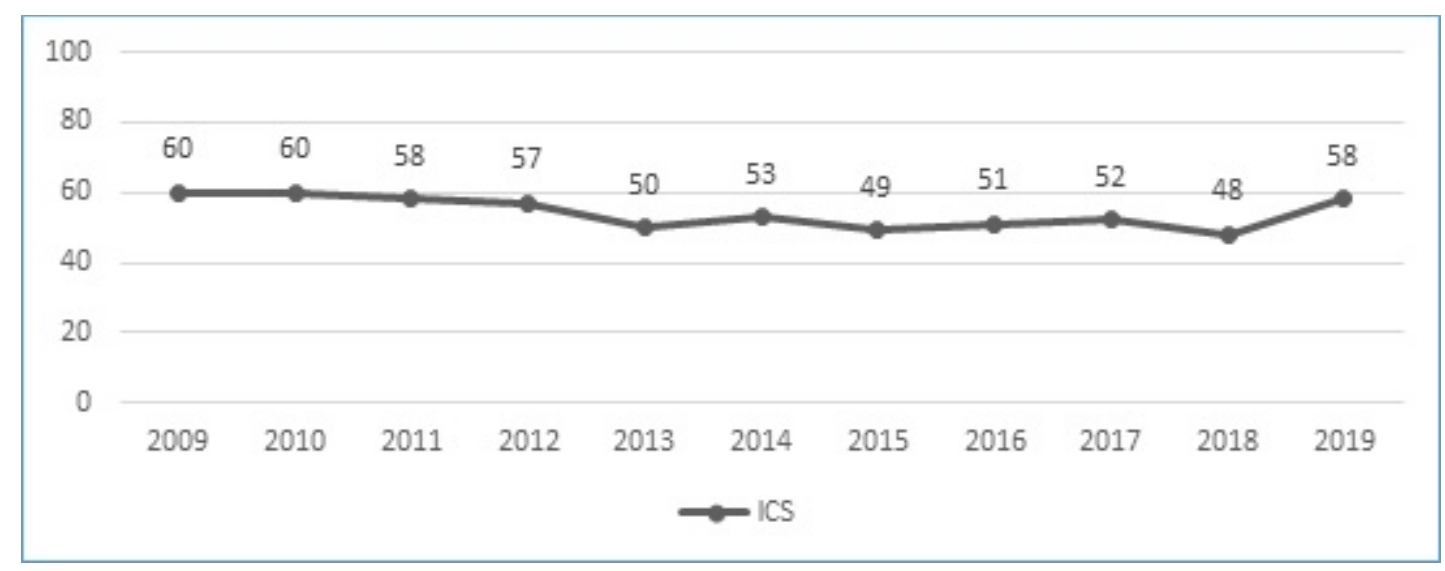

Gráfico 10 - Índice de Confiança Social. Fonte: IBOPE, 2019b

Sabe-se que a confiança como objeto de pesquisa apresenta diversas armadilhas teóricas e práticas (LUNDÂSEN, 2002), mas considerando que as expetativas e experiências dos cidadãos integram a segurança jurídica é necessário pesquisar tal elemento. Pela análise do Índice de Confiança Social constata-se que de 2009 a 2018 o cenário brasileiro era marcado pela desconfiança, mas em 2019 foi a confiança que subiu.

O descrédito das instituições democráticas brasileiras até 2018 também é apontado pelo Latinobarômetro ${ }^{7}$ que registrou uma queda no apoio à democracia no Brasil do ano de 2017 (43\%) para o ano de 2018 (34\%). Comparando-se 2017 e 2018 houve uma redução de 9\% no apoio à democracia (LATINOBARÓMETRO, 2018, p. 16). O índice de alguns anos anteriores, bem como o índice de 2019, não foram divulgados.

\footnotetext{
${ }^{6}$ Comparando-se os dados de 2018 com os de 2019, o ICS Pessoas e Grupos Sociais subiu 2 pontos, significando uma melhora de aproximadamente $3 \%$ na confiança.

${ }^{7}$ Sobre a metodologia da medição, o Latinobarômetro avalia a adesão explícita à democracia por meio de três alternativas: a primeira apoia o regime democrático, a segunda apoia o autoritarismo e a terceira manifesta indiferença ao tipo de regime. Secundariamente, o indicador mede o respaldo à frase de Winston Churchill sobre a democracia ser "o pior regime de governo exceto por todos os outros" (LATINOBARÓMETRO, 2018, p. 14) 


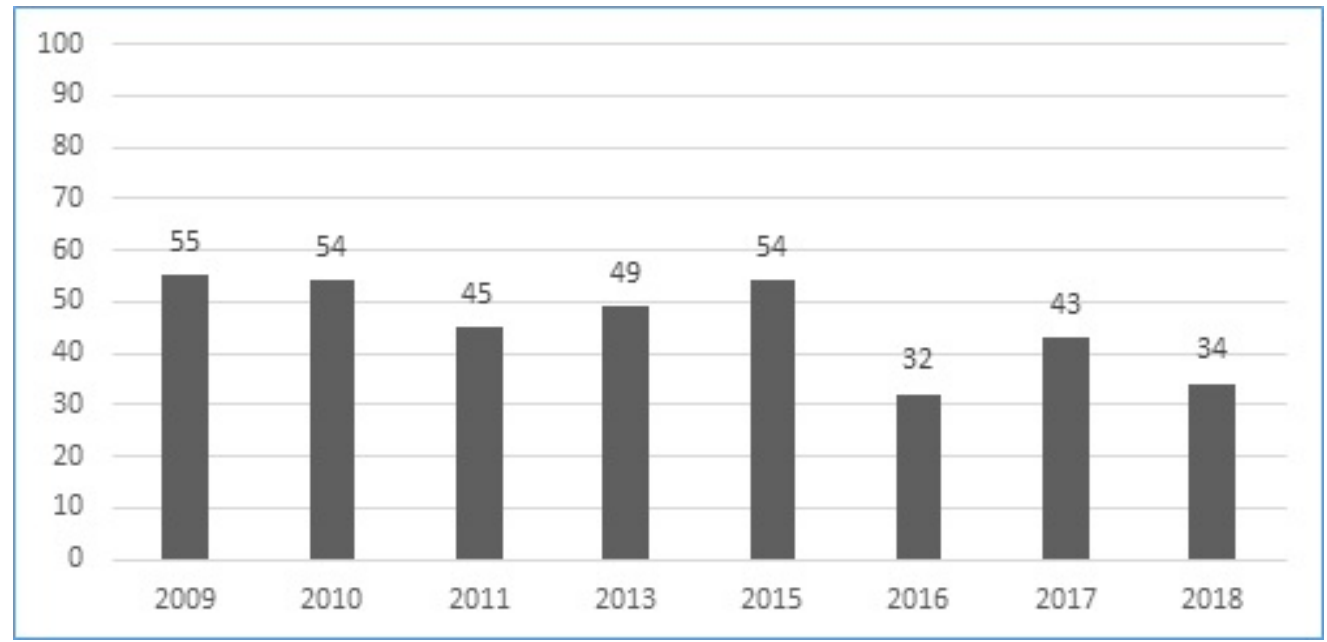

Gráfico 11 - Latinobarômetro: percentual de apoio à democracia no Brasil ${ }^{8}$. Fonte: LATINOBARÓMETRO, 2018

O Latinobarômetro também analisa a adesão dos cidadãos a partir da frase de Winston Churchill sobre a democracia ser "o pior regime de governo exceto por todos os outros" (LATINOBARÓMETRO, 2018, p. 14). Nesse indicador, a adesão brasileira à democracia está abaixo da média da América Latina desde o ano de 2015. Em 2018 a adesão registrada na América Latina era de 65\% enquanto no Brasil era de 56\% (LATINOBARÓMETRO, 2018, p. 31), mas sem os dados de 2019 não é possível verificar se houve alteração subsequente como aconteceu no Índice de Confiança Social.

A desconfiança e a insatisfação em relação à democracia geram distanciamento, cinismo e alienação e, nesse contexto, os cidadãos preferem alternativas anti-institucionais nas quais os partidos políticos e o parlamentarismo são relegados ao segundo plano enquanto o Poder Executivo assume o protagonismo com traços às vezes autoritários (MOISÉS, 2008, p. 39). É impossível e utópico tentar eliminar a desconfiança na democracia, mas existem alguns tipos de confiança que contribuem para a estabilidade, a viabilidade e a vitalidade da democracia - o desafio consiste em identificar esses tipos de confiança e os meios pelos quais as instituições democráticas devem germiná-las e mantê-las (WARREN, 1999, p. 310).

Uma possível explicação para a alteração dos Índice de Confiança Social em 2019 é a eleição presidencial, cujo vencedor utilizava frequentemente a palavra segurança em suas propostas e discursos. Entretanto, é preciso cautela para não transformar a segurança em uma cláusula de adesão incondicionada para medidas de controle social restritivas de liberdade (PÉREZ LUÑO, 1990, p. 337).

\footnotetext{
${ }^{8}$ Embora as medições desse item tenham se iniciado em 1995, o presente trabalho focará nos dados a partir de 2009 para se ajustar ao outro índice utilizado. 
Lado outro, não se sabe se o movimento ascendente da confiança se manterá nos próximos anos, pois a alteração do ISC pode ser fruto de um momento de otimismo. Para se manter a confiança, a segurança jurídica precisa ser incorporada nas rotinas estatais no intuito de proporcionar uma boa experiência democrática e a consequente adesão dos cidadãos, encerrando a erosão da autoridade estatal. A confiança não é o único elemento para aferição da segurança jurídica, mas a desconfiança evidenciada pelos indicadores representa um obstáculo a ela.

\section{Conclusão}

A segurança jurídica como princípio funciona como requisito e garantia da justiça política. Em sua dimensão política ela adquire contornos próprios que se relacionam com as experiências e expectativas dos cidadãos e, nesse contexto, as instituições democráticas desempenham um papel essencial para a segurança jurídica, especialmente em relação ao elemento da confiança. $\mathrm{O}$ descrédito das intuições repercute diretamente na adesão ao regime democrático por parte dos cidadãos e a desconfiança contínua torna questionável a autoridade das instituições democráticas. Os indicadores apontam que o Brasil estava sofrendo um declínio contínuo da confiança, mas em 2019 o resultado se alterou. Resta aguardar o desempenho das instituições nos próximos anos para verificar se a tendência se manterá.

Lado outro, a confiança não é o único elemento da segurança jurídica, sendo necessário observar todo o núcleo fundamental da Constituição de 1988, uma vez que estes também são princípios médios da justiça política. Sabe-se, porém, que os detentores do poder muitas vezes se afastam desse objetivo e, nesse contexto, as estratégias de justiça política buscam reforçar o compromisso institucional. A adesão dos cidadãos à democracia não virá pelo simples estabelecimento de regras e procedimentos, mas pela experiência positiva com as instituições democráticas.

\section{Referências}

BRASIL. Constituição da República Federativa do Brasil de 1988. Disponível em: http://www.planalto.gov.br/ccivil 03/constituicao/ConstituicaoCompilado.htm . Acesso em: 10 out. 2019.

CAMARGO, Margarida Maria Lacombe; BALARINI, Flávia Gonçalves. A segurança jurídica na doutrina e nos tribunais. XXI Congresso Nacional do Conpedi. Niterói, nov. 
2012. Disponível em: http://www.publicadireito.com.br/artigos/?cod=1f9b616faddedc02 . Acesso em: 09 jan. 2020.

CUNHA, Luciana Gross; OLIVEIRA, Fabiana Luci de. Justiça Eleitoral: opinião pública e confiança institucional. Cadernos Adenauer, XV, no 1, p. 191-210, 2014. Disponível em: https://www.kas.de/c/document_library/get_file?uuid=c41416bd-c7d9-2eb1-1e7997bea6d340f6\&groupId=265553 . Acesso em: 25 jan. 2020.

HÖFFE, Otfried. Justiça Política. Fundamentação de uma filosofia crítica do direito e do Estado. São Paulo: Martins Fontes, 2006.

INSTITUTO BRASILEIRO DE OPINIÃO PÚBLICA E ESTATÍSTICA - IBOPE. Brasileiro está mais confiante nas instituições. 07 ago. 2019. 2019a. Disponível em: http://177.47.5.246/noticias-e-pesquisas/brasileiro-esta-mais-confiante-nas-instituicoes/. Acesso em: 24 jan. 2020.

INSTITUTO BRASILEIRO DE OPINIÃO PÚBLICA E ESTATÍSTICA - IBOPE. Índice de Confiança Social 2019. 2019b. Disponível em:

http://www.ibopeinteligencia.com/arquivos/JOB\%2019 0844_ICS_INDICE_CONFIANCA SOCIAL 2019\%20-\%20Apresenta $\%$ C3\%A7\%C3\%A30\%20(final).pdf. Acesso em: 24 jan. 2020.

LATINOBARÓMETRO. Informe 2018. 2018. Disponível em: http://www.latinobarometro.org/latdocs/INFORME_2018_LATINOBAROMETRO.pdf. Acesso em: 25 jan. 2020.

LUHMANN, Niklas. Legitimação pelo procedimento. Brasília: Editora Universidade de Brasília, 1980.

LUNDÂSEN, Susanne. Podemos confiar nas medidas de confiança? Opinião Pública, v.8, n.2, p. 304-327, out. 2002. Disponível em: http://dx.doi.org/10.1590/S010462762002000200007 . Acesso em: 25 jan. 2020.

MARTINEZ, Vinicio C. Estado de Direito Político. Revista Urutágua, nº 06, p. 1-11 abr. jul. 2005. Disponível em: http://www.urutagua.uem.br/006/06martinez.htm . Acesso em: 09 jan. 2020.

MOISÉS, José Álvaro. Cidadania, confiança e instituições democráticas. Lua Nova, São Paulo, v. 65, p. 71-94, 2005. Disponível em: http://dx.doi.org/10.1590/S010264452005000200004 . Acesso em: 09 jan. 2020.

MOISÉS, José Álvaro; CARNEIRO, Gabriela Piquet. Democracia, desconfiança política e insatisfação com o regime - o caso do Brasil. Opinião Pública, v.14, nº 1, p. 1-42; jun. 2008. Disponível em: http://dx.doi.org/10.1590/S0104-62762008000100001 . Acesso em: 25 jan. 2020.

PÉREZ LUÑO, Antonio-Enrique. Seguridad jurídica y sistema cautelar. Doxa, n. 07, p. $327-$ 341, 1990. Disponível em: http://dx.doi.org/10.14198/DOXA1990.7.12 . Acesso em: 10 jan. 2020. 
WARREN, Mark E. Democratic theory and trust. In: WARREN, Mark E. (ed). Democracy and Trust. Cambridge: Cambridge University Press, 1999. p. 310-345.

Data de recebimento: 30.04 .2020

Data de aprovação: 27.08.2020 